\title{
Deformation Problem
}

National Cancer Institute

\section{Source}

National Cancer Institute. Deformation Problem. NCI Thesaurus. Code C92040.

Problems caused by changes in the shape or size of the device due to an applied force.

This can be a result of tensile forces, compressive forces, shear, bending, tensile (pulling), or torsion. 